\title{
STUDI ETNOFARMASI TUMBUHAN BERKHASIAT OBAT PADA SUKU BUTON DI KECAMATAN BINONGKO, KABUPATEN WAKATOBI, SULAWESI TENGGARA
}

\section{ETHNO PHARMACY STUDY OF HERBAL PLANT IN BURONESE, BINONGKO SUB-DISTRICT, WAKATOBI REGENCY OF SOUTH EAST SULAWESI}

\author{
Wa Ode Irma Indrayangingsih ${ }^{1 *}$, Nurlina Ibrahim ${ }^{1}$, Syariful Anam $^{1}$ \\ ${ }^{1}$ Jurusan Farmasi, Fakultas MIPA, Universitas Tadulako, Palu
}

Received 15 Juli 2015, Accepted 20 September 2015

\begin{abstract}
ABSTRAK
Studi etnofarmasi tumbuhan obat pada suku Buton telah dilakukan dari bulan Januari sampai April 2014 di Kecamatan Binongko, Kabuupaten Wakatobi, Sulawesi Tenggara. Penelitian ini bertujuan untuk mengetahui berbagai spesies dan organ tumbuhan yang dimanfaatkan, jenis-jenis penyakit yang diobati dan cara pemanfaatan tumbuhan obat oleh suku Buton di Kecamatan Binongko. Jenis penelitian ini adalah penelitian deskriptif yang menggunakan metode kualitatif dan teknik pengambilan sampel yakni snowball sampling melalui wawancara open-ended interview dengan 17 informan yang menggunakan media kuesioner. Berdasarkan hasil penelitian diketahui sebanyak 53 spesies tumbuhan dan terbagi dalam 35 famili yang dimanfaatkan sebagai obat. Tumbuhan yang paling banyak digunakan yaitu dari famili Euphorbiaceae sebanyak 6 spesies. Ditemukan 3 jenis tumbuhan yang khas dimanfaatkan antara lain Tali putri, daun picah dan kayu kuda. Organ tumbuhan yang dimanfaatkan antara lain daun, buah, batang, umbi, akar, rimpang, getah, bunga, kulit batang, dan kulit kayu. Organ tumbuhan yang paling banyak digunakan yaitu daun sebanyak 56\%. Cara penggunaannya yaitu direbus, ditumbuk, dikunyah, diperas, diiris, dioles, dibakar, diteteskan, direndam, dikonsumsi secara langsung, diparut, ditempelakan, diasap-asapi. Cara penggunaan yang paling banyak digunakan yaitu dengan cara direbus dan ditumbuk masing-masing $34 \%$.
\end{abstract}

Kata kunci : Etnofarmasi, Tumbuhan Obat, Suku Buton.

\begin{abstract}
Herbal plant ethno pharmacy study in Butonse has been coducted from January to april 2014 in Binongko Sub-districtm Wakatobi Regency of South East Sulawesi. This research aimed to find out various species and plant organs used, kinds of diseases healed, and the way to use the herbal plants by Butonese in Binongko Sub-district. This was a descripive research using qualitative method.The sample was taken through snowball technique with 17 informans by using questiomnaire. Based on the research result, it was obtained 53 species of plants and divided into 35 families that used as medicine.The most used plants were family of Euphorbiaceae of 6 species. It was found 3 kinds of unique plants used such as tali putri, daun picah, and kayu kuda. The organs used were leaf, fruit, stem, tuber, root, rhozome. Latex, flower, stem skin, and wood skin. The most used plant's organ was the leaves of $56 \%$. The wey is by boiling, pounding, chewing, squeezing, slicing, smearing, burning, dropping, soaking, consuming directly, gratting, attachng, and having smoke. The most way used is by boiling and pounding for $34 \%$ each.
\end{abstract}

Key words: Ethno pharmacy, plant herbal, Butonese.

*Corresponding Author : Wa Ode Irma Indrayaningsih wa.ode66@yahoo.co.id (ph: +62-851-4550-4512) 


\section{PENDAHULUAN}

Indonesia merupakan negara yang sangat kaya dengan tumbuh-tumbuhan yang memiliki banyak manfaat, khususnya dalam bidang kesehatan. Tercatat hanya ada lebih dari 7000 spesies tanaman yang dijadikan obat jamu pada saat sekarang ini, padahal kita tahu bahwa masih ada banyak tumbuh-tumbuhan lain hingga ratusan ribu yang bisa kita manfaatkan. Telah banyak dilakukan penelitian sebelumnya mengenai tumbuh-tumbuhan obat di Indonesia, tapi hingga saat ini belum ada pencatatan yang pasti mengenai tumbuh-tumbuhan tersebut (Anonim, 2013).

Langkah awal yang sangat membantu untuk menggali pengetahuan suku lokal terhadap resep tradisional berkhasiat obat yaitu dengan berbagai pendekatan secara ilmiah (Kuntorini, 2005). Salah satu pendekatan tersebut adalah etnofarmasi (Pieroni dkk., 2002). Pendekatan etnofarmasi telah dilakukan diberbagai suku di Indonesia, diantaranya yang telah diterapkan pada masyarakat lokal Suku Muna Kecamatan Wakarumba, Kabupaten Muna, Sulawesi Tenggara (Windadri dkk., 2006), dan di sekitar kawasan Gunung Gede Pangrango (Rosita dkk., 2007). Keduanya mendapatkan resep tradisional dari pengetahuan suku lokal tersebut.

Pemanfaatan tumbuhan sebagai obat tradisional disetiap daerah bahkan setiap etnis memiliki suatu pemahaman, pengetahuan bahkan pengalaman yang berbeda-beda. Misalnya suatu jenis tumbuhan obat yang digunakan oleh masyarakat di Kecamatan Binongko untuk mengobati penyakit tertentu, belum tentu digunakan oleh masyarakat di daerah lain untuk mengobati penyakit yang sama.

Obat tradisional telah lama dikenal dan digunakan oleh semua lapisan masyarakat Kecamatan Binongko, mulai dari anak-anak sampai orangtua sering menggunakan obat tradisional yang dikenal dengan sebutan 'Kombi Kampo' yang berarti obat kampung, akan tetapi saat ini hanya orang-orang tertentu saja, khususnya orangtua, yang masih menggunakan obat tradisional, sehingga pengetahuan tentang penggunaan obatobat tradisional sedikit demi sedikit mulai terabaikan. Hal ini disebabkan karena masuknya pengaruh kemajuan ilmu pengetahuan dan teknologi yaitu sudah terdapat obat sintetik (non herbal) yang dibuat secara moderen dan dikemas dalam kemasan yang menarik serta mudah dikonsumsi, sehingga pemanfaatan obat tradisional oleh masyarakat di Kecamatan Binongko saat ini mulai ditinggalkan.

Oleh karena itu, agar kelestarian pengetahuan maupun penggunaan tumbuhtumbuhan sebagai obat tradisional tetap terjaga dan dapat digunakan sebagai referensi dasar pengembangan obat baru, maka penulis tertarik melakukan penelitian dengan judul studi etnofarmasi tumbuhan berkhasiat obat pada Suku Buton di Kecamatan Binongko, Kabupaten Wakatobi, Sulawesi Tenggara.

\section{METODE PENELITIAN}

Penelitian ini adalah penelitian deskriptif yang menggunakan metode kualitatif. Metode kualitatif digunakan untuk mengetahui penggunaan tumbuhan yang diketahui atau digunakan oleh masyarakat suku Buton di desa Kampokampo, Lagongga, Jaya Makmur, one-one dan Makoro sebagai obat (Sudjatno dalam Anam, 2011).

Teknik pengambilan sampel yakni snowball sampling. Dalam penentuan sampel, pertama-tama dipilih satu orang sampel, karena belum lengkap data yang diberikan, maka peneliti mencari orang lain yang dipandang lebih tau dan dapat melengkapi data yang diberikan oleh sampel sebelumnnya (Sugiyono, 2007).

Teknik wawancara dilakukan dengan menggunakan open-ended interview. Dari studi lapangan yang dilakukan, para informan ditanya tentang nama lokal, organ yang dimanfaatkan dan cara pemanfaatan tumbuhan tersebut sebagai obat dalam menyembuhkan suatu 
penyakit. Hal ini dilakukan dengan menggunakan media kuesioner.

\section{HASIL DAN PEMBAHASAN \\ Hasil}

Berdasarkan hasil identifikasi spesimen yang dilakukan di UPT sumber daya hayati Sulawesi Universitas Tadulako didapatkan sebanyak 35 famili tumbuhan, yang terdiri dari 53 jenis tumbuhan obat yang digunakan oleh masyarakat Suku Buton di Kecamatan Binongko Kabupaten Wakatobi Sulawesi Tenggara.

Tabel 1. Famili, Spesies, Khasiat, dan Organ Tumbuhan Obat yang Digunakan Oleh Masyarakat Suku Buton di Kecamatan Binongko, Kabupaten Wakatobi, Sulawesi Tenggara

\begin{tabular}{|c|c|c|c|}
\hline Famili & Nama spesies / Nama Lokal & $\begin{array}{c}\text { Organ tumbuhan yang } \\
\text { digunakan }\end{array}$ & Penyakit yang Diobati \\
\hline Amaranthaceae & Amaranthus sp. (Baeya) & Semua organ tumbuhan & Paru-paru basah \\
\hline \multirow[t]{6}{*}{ Euphorbiaceae } & Euphorbia tithymaloides L. (Pinso-pinso mata) & Getah & Digigit serangga berbisa \\
\hline & Acalypha indica L. (Dali-dali) & Semua organ tumbuhan & Patah Tulang \\
\hline & Euphorbia heterophylla L. (Bera-bera) & Daun & Penuruun berat badan \\
\hline & Jatropha gossypiifolia L. (Sulu Meha) & Daun, Getah & $\begin{array}{l}\text { Demam, Sakit gigi, } \\
\text { Sakit telinga, Luka } \\
\text { bakar, sariawan. }\end{array}$ \\
\hline & Jatropha curcus L. (Sulu) & Daun & Panas dalam \\
\hline & Manihot esculenta Crantz. (Kanokau) & Daun & Mencret \\
\hline \multirow[t]{2}{*}{ Lythraceae } & Punica granatum L. (Jalima) & $\begin{array}{l}\text { Buah, Pucuk daun, } \\
\text { Bunga }\end{array}$ & $\begin{array}{l}\text { Muntah darah, Mencret, } \\
\text { Cacingan, Batuk, Sakit } \\
\text { telinga. }\end{array}$ \\
\hline & Lawsonia inermis L. (Patirangga) & Daun & $\begin{array}{l}\text { Luka baru, Memulihkan } \\
\text { suara, Bantahan. }\end{array}$ \\
\hline Cucurbitaceae & Cucurbita moschata Duchesne. (Labu) & Daun & Darah tinggi \\
\hline Verbenaceae & Lantana camara L. (Kambaragi) & Daun & $\begin{array}{l}\text { Luka baru, Kencing } \\
\text { manis }\end{array}$ \\
\hline \multirow[t]{2}{*}{ Moraceae } & $\begin{array}{l}\text { Artocarpus altilis (Parkinsom ex F.A.Zorn) } \\
\text { Fosberg. (Suku) }\end{array}$ & Daun & Darah tinggi \\
\hline & Ficus septica Burm.f. (Kotti) & Daun & Demam \\
\hline Passifloraceae & Passiflora foetida L. (Bambakuru) & Daun & Kencing manis \\
\hline Caricaceae & Carica papaya L. (Kasitela) & Daun, akar & Malaria \\
\hline \multirow[t]{3}{*}{ Lamiaceae } & Ocimum sanetum Linn. (Dalimata) & Daun & Batuk, Flu \\
\hline & Orthosiphon aristatus (Blume) Miq. (Hofo) & $\begin{array}{l}\text { Semua organ tumbuhan, } \\
\text { Daun. }\end{array}$ & $\begin{array}{l}\text { Patah tulang, kencing } \\
\text { manis. }\end{array}$ \\
\hline & Melissa officinalis L. (Talo) & Daun & $\begin{array}{l}\text { Panas dalam, Sariawan, } \\
\text { Flu, Sakit telinga }\end{array}$ \\
\hline Rubiaceae & Morinda citrifolia L. (Fangkudu) & Daun & $\begin{array}{l}\text { Sakit kuning, Bengkak } \\
\text { pada perut }\end{array}$ \\
\hline Crassulaceae & $\begin{array}{l}\text { Bryophyllum pinnatum (Lam.) Oken. } \\
\text { (Kamodindi) }\end{array}$ & Daun & $\begin{array}{l}\text { Demam, Sakit telinga, } \\
\text { Bisul. }\end{array}$ \\
\hline Myrtaceae & Psidium guajava L. (Gayawasi) & Daun, Buah & Mencret \\
\hline Arecaceae & Cocos mucifera L. (Kaluku) & Buah & Alergi, maag \\
\hline \multirow[t]{2}{*}{ Zingiberaceae } & Zingiber sp. (Loia) & Rimpang & Maag \\
\hline & Curcuma domestica Val (Lulu) & Rimpang & Pelancar haid \\
\hline Oleaceae & Jasminum sambac (L.) Aiton (Kamba Manuru) & Daun & Bisul \\
\hline Anacardiaceae & $\begin{array}{l}\text { Lannea coromandelica (Houtt.) Merr. (Kau } \\
\text { java) }\end{array}$ & Btang, Kulit batang & $\begin{array}{l}\text { Muntah darah, kudis, } \\
\text { mencret. }\end{array}$ \\
\hline \multirow[t]{2}{*}{ Solanaceae } & Physalis angulata L. (Kapupuena) & Daun, akar. & Cacar air \\
\hline & Datura metel L. (Tolu pande) & Daun & Sakit telinga \\
\hline Moringaceae & Moringa oleifera Lam. (Kaudafa) & Daun, batang & Memar, Patah tulang \\
\hline Combretaceae & Terminalia catappa L. (Tolie) & Daun & Rematik \\
\hline Oxalidaceae & Averrhoa bilimbi L. (Tangkulela) & Daun, Bunga & $\begin{array}{l}\text { Darah tinggi, Batuk } \\
\text { pada anak-anak }\end{array}$ \\
\hline \multirow[t]{2}{*}{ Asteraceae } & Gymura sp. (Bunga) & Daun & Luka baru \\
\hline & $\begin{array}{l}\text { Bidens biternata (Lour) Merr.\& Sheff. (Ulo } \\
\text { liku) }\end{array}$ & Daun & Sakit telinga \\
\hline Piperaceae & Piper sp. (Soilo) & Daun & $\begin{array}{l}\text { Menghilangkan bau } \\
\text { mulut, Keputihan }\end{array}$ \\
\hline
\end{tabular}




\begin{tabular}{|c|c|c|c|}
\hline & Peperomia pellucida (L.) Kunth. (Luntu-luntu) & Semua organ tumbuhan & Panas dalam \\
\hline Poaceae & Cymbopogon nardus (L.) Rendle. (Padamalala) & Akar & Patah tulang \\
\hline \multirow[t]{2}{*}{ Phyllanthaceae } & Phyllanthus sp. (Sampa-sampalu) & Daun & $\begin{array}{l}\text { Kencing manis, muntah } \\
\text { darah }\end{array}$ \\
\hline & Sauropus androgynous (L.) Merr. (Karato) & Daun & Demam berdarah \\
\hline Amaryllidaceae & Crinum asiaticum $\mathrm{L}$. (Rumpi) & Daun & $\begin{array}{l}\text { Mengeluarkan racun } \\
\text { dalam tubuh }\end{array}$ \\
\hline Apocynaceae & Alstonia scholaris (L.) R.Br. (Ritta) & Getah, kulit kayu & Bisul, kencing manis \\
\hline \multirow[t]{2}{*}{ Xanthorrhoeaceae } & Alloe vera (L.) Burm.f. (Lidah buaya) & Daun & Batu ginjal \\
\hline & Sesbania grandiflora (L.) Pers. (Kamba java) & Daun & Keseleo, patah tulang \\
\hline \multirow[t]{2}{*}{ Leguminosae } & Desmodium gangeticum (L.) DC (Impo-impo) & Daun & Kencing batu \\
\hline & Tamarindus indica, Linn. (Sampalu) & Buah & Demam \\
\hline Polypodiaceae & Drynaria sp. (Sasapi) & Akar & Susah buang air besar \\
\hline Acanthaceae & Baleria prionitis L. (Guranta) & Daun & Sakit gigi dan Sariawan \\
\hline Cacataceae & Pereskia bleo (Kunth) DC. (hofo) & Buah & Pembesih kandungan \\
\hline \multirow[t]{2}{*}{ Annonaceae } & Annona muricata L. (Sirikaea falanda) & Daun & Bisul, sakit pinggang. \\
\hline & Annona squamosa L. (Sirikaea) & Daun & $\begin{array}{l}\text { Panas dalam, sakit } \\
\text { telinga }\end{array}$ \\
\hline Lauraceae & Cassytha filiformis L. (Puka-puka) & Semua organ tumbuhan & Kencing darah \\
\hline \multirow[t]{2}{*}{ Liliaceae } & Allium cepa L. (Bafa meha) & Umbi & Sakit perut \\
\hline & Allium sativum L. (Bafa mohute) & Umbi & $\begin{array}{l}\text { Darah tinggi, sakit } \\
\text { kepala }\end{array}$ \\
\hline Rutaceae & $\begin{array}{l}\text { Citrus aurantifolia (Christm) Swingle. (Munte } \\
\text { kikisi) }\end{array}$ & Buah & $\begin{array}{l}\text { Batuk, kolestrol, } \\
\text { pencegah infeksi }\end{array}$ \\
\hline
\end{tabular}

Tabel.2. Persentase Organ Tumbuhan Obat yang Digunakan Oleh Masyarakat Suku Buton di Kecamatan Binongko, Kabupaten Wakatobi, Sulawesi Tenggara

\begin{tabular}{|c|c|c|c|}
\hline $\begin{array}{c}\text { Bagian Tumbuhan } \\
\text { Yang digunakan }\end{array}$ & Persentase & $\begin{array}{c}\text { Bagian Tumbuhan } \\
\text { Yang digunakan }\end{array}$ & Persentase \\
\hline Daun & $56 \%$ & Rimpang, bunga, batang, kulit kayu & $2 \%$ \\
\hline Buah & $12 \%$ & Getah & $6 \%$ \\
\hline Umbi & $3 \%$ & Semua organ tumbuhan & $1 \%$ \\
\hline Akar & $4 \%$ & Kulit batang & $5 \%$ \\
\hline
\end{tabular}

\section{Pembahasan}

Berdasarkan hasil penelitian yang diperoleh dari hasil wawancara pada 17 informan yang dilakukan pada masyarakat suku buton di Kecamatan Binongko yaitu 35 famili dari 53 jenis tumbuhan yang digunakan sebagai obat. Tumbuhan obat tersebut tumbuh dipekarangan rumah, maupun diperkebunan warga. Di Kemacatan Binongko masyarakat ynng menggunakan tumbuhan obat yaitu orangtua, masyarakat yang rumahnya jauh dari rumah sakit, puskesmas, dan berekonomi lemah.

Jenis tumbuhan obat yang paling banyak digunakan yaitu dari famili Euphorbiaceae sebanyak 6 spesies, famili Lamiaceae, Leguminosae sebanyak 3 spesies, famili Lythraceae, Moraceae, Zingiberaceae, Solanaceae, Asteraceae,
Piperaceae, Phyllanthaceae, Annonaceae, Liliaceae sebanyak 2 spesies, dan yang paling sedikit digunakan sebagai tumbuhan obat yaitu dari famili Amaranthaceae, Cucurbitaceae, Verbenaceae, Passifloraceae,

Caricaceae,Rubiaceae,Crassulaceae,Myrta ceae,Arecaceae,Oleaceae,Anacardiaceae, Moringaceae,Combretaceae,Oxalidaceae, $\mathrm{P}$ oaceae,Amaryllidaceae,Apocynaceae,Xant horrhoeaceae,Polypodiaceae,Acanthaceae, Cacataceae,Lauraceae, Rutaceae masingmasing sebanyak 1 spesies.

Semua organ dari tumbuhan yang digunakan oleh masyarakat suku Buton di Kecamatan Binongko sebagai bahan obat berbeda-beda yaitu daun, akar, umbi, rimpang, batang, kulit batang, buah, getah, bunga, kulit kayu dan semua organ 
tumbuhan. Adapun organ tumbuhan yang paling banyak digunakan masyarakat sebagai pengobatan adalah daun sebanyak $56 \%$. Daun merupakan organ tumbuhan yang banyak digunakan sebagai obat tradisional karena daun umumnya bertekstur lunak mempunyai kandungan air yang tinggi (70-80\%). Zat yang banyak terdapat pada daun adalah minyak atsiri, fenol, senyawa kalium dan klorofil. Keuntungan lain dari daun adalah memiliki serat yang lunak, sehingga mudah untuk mengekstrak zat-zat yang akan digunakan sebagai obat (Handayani, 2003). Masyarakat Suku Buton mengolah organ daun dengan cara direbus, ditumbuk, dikunyah, diperas, diiris, dioles, dibakar, diteteskan, direndam, dikonsumsi secara langsung, diparut, ditempelkan, diasapasapi. Adapun penyakit-penyakit yang dapat diobati dengan menggunakan organ tumbuhan daun yaitu darah tinggi, demam, batuk, mencret, sariawan, luka, sakit telinga, bisul, flu, rematik, keputihan dan kencing manis dan lain-lain.

Tumbuhan obat yang digunakan oleh masyarakat suku Buton di kecamatan Binongko tidak hanya digunakan untuk 1 atau 2 macam penyakit saja, tetapi digunakan untuk pengobatan beberapa macam penyakit. Pada tabel 1 menunjukkan bahwa terdapat 46 macam penyakit dengan 87 ramuan tradisional. Ramuan tersebut telah digunakan sebagai obat tradisional secara turun temurun yang didalamnya terdapat berbagai jenis tumbuhann. Tumbuhan yang digunakan sebagai ramuan tradisional dalam bentuk tunggal dan campuran dengan tumbuhan lainnya. Terdapat beberapa contoh cara pengolahan dan ramuan obat yang digunakan oleh Suku Buton diantara:

1. Paru-paru basah
Bayam (Amaranthus sp) berasal dari famili Amaranthaceae pada suku Buton digunakan untuk mengobati penyakit paru-paru basah. Semua organ tumbuhan bayam dicuci bersih, kemudian direbus dengan air 3 gelas hingga menjadi 1 gelas, lalu disaring. Air hasil saringan diminum 2 kali sehari pagi dan sore setelah makan.

2. Patah Tulang

Rimpang kunyit (Curcuma domestica Val.) dari famili Zingiberaceae ditambah daun turi (Sesbania grandiflora (L.). Pers) dari famili Leguminosae dalam satu tempat kemudian di tumbuk sampai halus. Hasil dari tumbukan yang sudah halus dioleskan pada bagian tubuh yang patah.

3. Kencing darah

Semua organ tumbuhan tali putri (Cassytha foliformis L.) dari famili Lauraceae digunakan untuk mengobati penyakit kencing darah. Semua organ tumbuhan dicuci bersih kemudian direbus dengan air 3 gelas hingga menjadi 1 gelas. Air hasil rebusan disaring kemudian diminum 2 kali sehari.

4. Kencing manis

Kulit kayu pulai (Alstonia scholaris (L.) R.Br.) dari famili Apocynaceae dicuci bersih, kemudian direbus dengan air 3 gelas hingga menjadi 1 gelas. Air rebusan disaring kemudian diminum 2 kali sehari.

5. Muntah Darah

Batang kayu kuda (Lamea coromandelica (Hout.) Merr) dari famili Anacardiaceae dicuci bersih kemudian direbus dengan air 3 gelas hingga menjadi 1 gelas. Air rebusan disaring kemudian d minum 2 kali sehari. 
6. Pelancar Haid

Rimpang kunyit (Curcuma domestica Vall) dari famili Zingiberaceae ditumbuk sampai halus, setelah halus ditambahkan asam jawa (Tamarindus indica L.) dari famili Leguminosae, kemudian diperas. Hasil air perasannya diminum 2 kali sehari.

7. Kencing batu

Daun picah (Desmodium gangeticum (L.) DC) dari famili Leguminosae dicuci bersih kemudian direbus dengan air 3 gelas hingga menajdi 1 gelas. Air hasil rebusan disaring kemudian diminum 2 kali sehari.

8. Demam Berdarah

Daun katuk (Sauropus androgynous (L.) Merr) dari famili Phyllanthaceae dicuci bersih kemudian direbus dengan air 3 gelas hingga menjadi 1 gelas. Air hasil rebusan disaring lalu diminum 2 kali sehari.

9. Keputihan

Daun sirih (Piper betle L.) dari famili Piperaceae direbus. Air rebusannya dinginkan kemudian dibasuhkan pada alat kemaluan.

\section{DAFTAR PUSTAKA}

Anam, S., Alam, G., Pitopang, R., Yusriadi., Zubair, S. (2011). Kajian Etnofarmakologi Tumbuhan Berkhasiat Obat di Kawasan Lembah Palu. Program Studi Farmasi MIPA Universitas Tadulako. Palu.
Anonim. (2013). Lembaga Penelitian dan Pengabdian Masyaraka. Workshop Pengumpul Data Riset Khusus Eksplorasi Pengetahuan Lokal Etnomedisin dan Tumbuhan obat di Indonesia Berbasis Komunitas. http://www.qadryqade.com/2013/0 2/ristoja-2012.html

Handayani. (2003). Membedah rahasia Ramuan madura. Agromedia Pustaka Jakarta.

Kuntorini, E.M. (2005). Botani Ekonomi Zingiberaceae Sebagai Obat Tradisional Oleh Mssyarakat Di Kecmatan Banjarbaru. Biostianceae

Pieroni, A., Ouave, C., Nebel, S., \& Henrich, M. (2002). Ethnopharmacy of the Ethnic Albanians (Arbereshe) of Northern Basilicata. Italy.

Rosita, S. M. D., Rostiana, O., Pribadi, \& Hernani. (2007). Penggalian IPTEK Etnomedisin Di Gunung Gede Pangrango. Bul. Littro.

Sugiyono. (2007). Memahami Penelitian Kualitatif. Alfabeta. Bandung.

Windadri, F. L., Rahayu, M., Uji, T. \& Rustiami, H. (2006). Pemanfaatan Tumbuhan Sebagai Bahan Obat Oleh Masyarakat Lokal Suku Muna Di Kecamatan Wakarumba, Kabupaten Muna. Sulawesi Tenggara. Biodiversitas 7 (4); 333 339. 